\title{
Analysis of Perioperative Risk Factors in Mortality and Morbidity after Modified Bentall Operation
}

\author{
Anil Z. Apaydin, ${ }^{1}$ MD, Hakan Posacioglu,${ }^{1}$ MD, Fatih Islamoglu,${ }^{1}$ MD, \\ Tanzer CALKavur, ${ }^{1}$ MD, Tahir YAGDI, ${ }^{1} \mathrm{MD}$, Suat BuKET, ${ }^{1} \mathrm{MD}$, \\ and Isa DURMAZ, ${ }^{1} \mathrm{MD}$
}

\begin{abstract}
SUMMARY
The objective of the present study was to determine the risk factors for operative and short-term mortality, and morbidity after a Bentall operation. Between July 1994 and February 2001, 86 consecutive patients (70 males) underwent a modified Bentall operation at our hospital. The aortic pathology was acute aortic dissection in $12(14 \%)$, chronic dissection in $9(10.5 \%)$ and degenerative aneurysm in $65(75.6 \%)$. Mean age was $48 \pm 15$ years. Eleven preoperative, 8 intraoperative and 6 postoperative variables of these patients were retrospectively analyzed using univariate and multivariate logistic regression analysis. Six patients died in the hospital $(6.9 \%)$ and 2 died within four months after being discharged from the hospital. Mean follow-up time was $33 \pm 23$ months ( 2 months to 8 years). The survival rate among hospital survivors was $88 \%$ at 3 years and $77 \%$ at 6 years. Univariate predictors of in-hospital and short-term mortality were the presence of aortic valve calcification, stenotic aortic valves, renal failure, and cardiac failure after the operation. Multivariate analysis revealed no independent risk factors. Risk factors for morbidity were etiology of acute dissection, use of circulatory arrest, transfusion of blood and fresh frozen plasma more than 2 units each, cross clamp and cardiopulmonary bypass times (exceeding 90 and 140 minutes, respectively), and performing concomitant procedures.

Modified Bentall procedures are safe in general. Meticulous dissection, careful handling and positioning of the coronary buttons are of paramount importance in patients with stiff aortic root since technical errors are more likely to occur. (Jpn Heart J 2002; 43: 151-157)
\end{abstract}

Key words: Aortic root replacement, Mortality and morbidity, Risk analysis

AORTIC root replacement with a composite graft is a complex procedure. Although excellent results after elective repair for young Marfan's patients have been reported, overall mortality in some series is around $10 \% .^{1-3)}$ We have retrospectively reviewed our results with 86 consecutive patients who underwent a

From the ${ }^{1}$ Department of Cardiovascular Surgery, Ege University Medical School, Izmir, Turkey.

Address for correspondence: Anil Apaydin, MD, Department of Cardiovascular Surgery, Ege University Medical School, Izmir 35100 Turkey.

Received for publication October 19, 2001.

Revised and accepted November 19, 2001. 
Bentall procedure in order to determine the risk factors for operative and shortterm mortality, and morbidity.

\section{MATERIALS AND Methods}

Between July 1994 and February 2001, 86 consecutive patients underwent a modified Bentall operation (button Bentall in 83, Cabrol in 3 patients). Patients who underwent total arch replacements together with the Bentall operation were excluded from the study. The mean age of the patients was $48 \pm 15$ years (range 15 to 78 years). Seventy patients were male and 16 were female. The aortic pathology requiring aortic root replacement was acute aortic dissection in $12(14 \%)$ patients, chronic dissection in $9(10.5 \%)$, and degenerative aneurysm in 65 $(75.6 \%)$.

\section{Descriptions of terms in the analysis:}

Mortality: In-hospital as well as short-term deaths among hospital survivors. The short-term mortality was included in the risk analysis with an assumption that it may be secondary to the procedure-related events.

Morbidity: Dysrhythmia was defined as persistent ventricular tachycardia or fibrillation causing hemodynamic instability. Renal failure was defined as a need for dialysis. Respiratory failure was defined as a ventilation requirement exceeding 3 days, development of adult respiratory distress syndrome, or need for tracheotomy. Cardiac failure was defined as a low output state despite inotropic or intraaortic balloon pump support despite optimum volume status. Temporary neurological dysfunction was defined as transient confusion, agitation, lethargy or obtundation not associated with stroke.

Left ventricular dysfunction was defined as an ejection fraction of less than $35 \%$, or a dilated ventricle due to aortic insufficiency or ischemia.

Surgical technique: After a median sternotomy and administration of systemic heparin, the right atrium and the ascending aorta or the femoral artery were cannulated. Cardiopulmonary bypass was initiated. The ascending aorta was crossclamped just below the innominate artery. During cooling, the aneurysm was opened and antegrade blood cardioplegia was administered into the coronary artery ostia. Myocardial preservation was achieved by intermittent administration of retrograde coronary sinus cardioplegia. The right superior pulmonary vein was used to vent the left heart. Composite grafts containing bileaflet mechanical valves and either gelatin precoated or collagen impregnated Dacron material were used in all replacements. In patients undergoing the Cabrol procedure, 10 $\mathrm{mm}$ Dacron grafts were used for coronary reattachments. After preparation of the coronary buttons and resection of the valve leaflets, a composite graft was sutured to the aortic annulus with pledgeted 2-0 polyester sutures. First, the left 
coronary artery button and then the right button was anastomosed to the openings made on the composite graft in an end-to-side fashion with running 4-0 polypropylene sutures. These anastomoses were buttressed with thin strips of Teflon felt. The open distal end of the composite graft was closed with a straight cross-clamp by leaving a small gap for insertion of the cardioplegia cannula. High pressure cardioplegia was given to check the coronary button anastomoses for possible leakage. Next, the composite graft was cut to the appropriate length. The distal ascending aorta was completely transected. If an aortic dissection or arch aneurysm was present, the patient was cooled down to a rectal temperature of $15^{\circ} \mathrm{C}$ during aortic root reconstruction. The cross-clamp was released after the initiation of HCA and an open distal anastomosis was performed end-to-end with a 30 polypropylene suture. For others, distal anastomosis was performed under cross-clamp and the rectal temperature was kept around $28^{\circ} \mathrm{C}$. After evacuation of air from the aortic graft, the patient was warmed and weaned from the cardiopulmonary bypass. Concomitant cardiac procedures were coronary bypass grafting in 11 patients, mitral valve replacement in 1, mitral ring annuloplasty in 1 and repair of subaortic VSD in 1. Creation of a perigraft space-right atrial fistula was performed in one patient using a pericardial patch. The mean duration of CPB was $150 \pm 44$ minutes and that of aortic cross-clamp was $107 \pm 28$ minutes.

Eleven preoperative, 8 intraoperative, and 6 postoperative variables of these patients were analyzed.

Follow-up: The status of hospital survivors was determined by either a visit to our cardiology department or phone contact. Follow-up was complete in 70 of 80 hospital survivors (87\%). Mean follow-up time was $33 \pm 23$ months (2 months to 8 years).

Statistical analysis: Statistical analysis was performed using an SPSS/PC+ (ver 7.5) computer program. Continuous data were analyzed using Student's $t$ test. Discrete data were analyzed by chi-square or Fisher's exact test when applicable. All factors were assessed for their ability to predict perioperative variables using a logistic regression model that was suited for each variable and multivariate logistic regression analysis. All results are expressed as the mean \pm standard deviation. Values of $p<0.05$ were considered to be statistically significant. Survival rates were calculated using the Kaplan-Meier method.

\section{RESUlts}

Six patients died in the hospital (6.9\%). Among the hospital survivors, one each died 2 and 4 months after being discharged from the hospital. These were included in the analysis. Mortality including the short-term deaths was $9.3 \%$. A seventy-two year old patient with acute type A dissection who presented with 
rupture died of multiorgan failure. One patient with an aneurysm fistulized to the pulmonary artery who had undergone redo Cabrol procedure developed respiratory failure requiring tracheostomy and died of sudden cardiac arrest while on ventilatory support. One patient died due to intractable ventricular dysrhythmia in the early postoperative period. Three patients with calcified bicuspid valves died due to cardiac failure. One of these patients had severe three-vessel coronary disease with poor LV function. Both patients who died suddenly 2-4 months after hospital discharge had dilated ventricles with poor function suggesting that the cause of death could possibly be ventricular fibrillation. There were 8 late deaths other than the two above-mentioned short-term deaths. The cause of death was endocarditis in 2, stroke in 2, chronic obstructive lung disease in 1, and cardiac failure in 3 . The survival rate among hospital survivors was $88 \%$ at 3 years and $77 \%$ at 6 years. Actuarial survival of the hospital survivors is shown in Figure 1.

Univariate predictors of in-hospital and short-term mortality were the presence of aortic valve calcification, stenotic aortic valves, renal failure, and cardiac failure after the operation (Tables I and II). Factors found to be univariate predic-

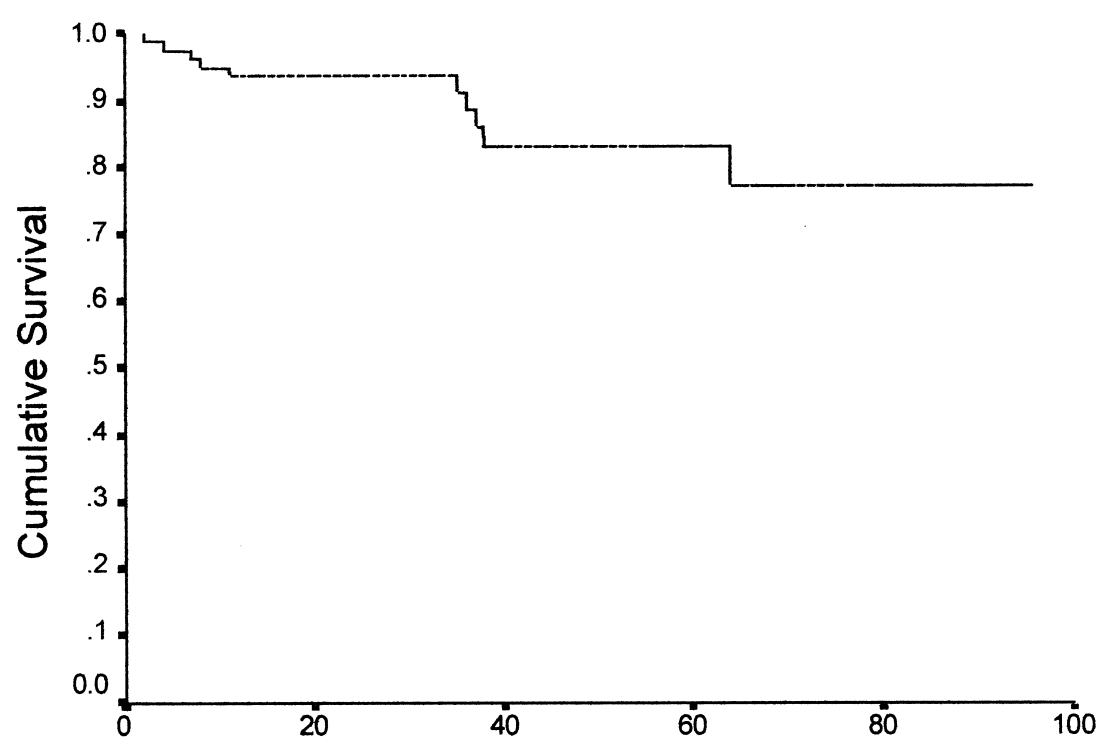

Months after Operation

Figure 1. Actuarial survival rate of hospital survivors. 
Table I. Preoperative and Operative Univariate Risk Factors for Mortality and Morbidity

\begin{tabular}{|c|c|c|c|c|c|c|}
\hline \multicolumn{2}{|c|}{ Preoperative and OperativeVariables } & \multirow{2}{*}{$\begin{array}{l}\text { Number of } \\
\text { patients }\end{array}$} & \multicolumn{2}{|c|}{ Mortality } & \multicolumn{2}{|c|}{ Morbidity } \\
\hline & & & Deaths & $p$ & Patients & $p$ \\
\hline \multirow[t]{2}{*}{ Gender } & Male & 70 & 6 & 0.63 & 20 & 0.48 \\
\hline & Female & 16 & 2 & & 6 & \\
\hline Age $\geq 65$ & & 16 & 2 & 0.46 & 6 & 0.33 \\
\hline \multirow[t]{3}{*}{ Etiology } & Degenerative & 65 & 6 & & 18 & \\
\hline & Acute dissection & 12 & 1 & 0.97 & 7 & 0.044 \\
\hline & Chronic dissection & 9 & 1 & & 1 & \\
\hline \multicolumn{2}{|c|}{ Coronary artery disease } & 12 & 2 & 0.34 & 3 & 0.47 \\
\hline \multicolumn{2}{|c|}{ LV dysfunction } & 28 & 3 & 0.75 & 6 & 0.21 \\
\hline \multicolumn{2}{|c|}{ Calcification of aortic valve-annulus } & 14 & 5 & 0.002 & 5 & 0.42 \\
\hline \multicolumn{2}{|c|}{ AS } & 5 & 1 & & 2 & \\
\hline \multicolumn{2}{|c|}{ AS + Mild to moderate AI } & 15 & 4 & 0.042 & 3 & 0.58 \\
\hline \multicolumn{2}{|c|}{ AI } & 65 & 3 & & 21 & \\
\hline \multicolumn{2}{|c|}{ Marfan Syndrome } & 13 & 1 & 0.65 & 5 & 0.52 \\
\hline \multicolumn{2}{|c|}{ Bicuspid aortic valve } & 23 & 4 & 0.12 & 9 & 0.2 \\
\hline \multicolumn{2}{|c|}{ Coexisting systemic disease } & 23 & 2 & 0.6 & 7 & 0.83 \\
\hline \multicolumn{2}{|c|}{ Reoperation } & 10 & 2 & 0.23 & 2 & 0.36 \\
\hline \multicolumn{2}{|c|}{ Concomitant procedures } & 14 & 2 & 0.38 & 5 & 0.62 \\
\hline \multicolumn{2}{|c|}{ Valve size $\leq 23 \mathrm{~mm}$} & 16 & 2 & 0.46 & 8 & 0.057 \\
\hline \multicolumn{2}{|c|}{ Use of HCA } & 42 & 6 & 0.11 & 18 & 0.013 \\
\hline \multicolumn{2}{|c|}{$X$-clamp time $>90$ minutes } & 62 & 7 & 0.28 & 23 & 0.02 \\
\hline \multicolumn{2}{|c|}{ CPB time $>140$ minutes } & 37 & 1 & 0.06 & 7 & 0.04 \\
\hline \multicolumn{2}{|c|}{ Tx of blood $>2$ units } & 25 & 4 & 0.16 & 14 & 0.001 \\
\hline \multicolumn{2}{|c|}{ Tx of FFP $>2$ units } & 16 & 3 & 0.16 & 9 & 0.016 \\
\hline
\end{tabular}

$\mathrm{AS}=$ aortic stenosis; $\mathrm{AI}=$ aortic insufficiency; $\mathrm{Tx}=$ Transfusion; $\mathrm{FFP}=$ Fresh frozen plasma; $\mathrm{X}$-clamp=cross-clamp; $\mathrm{CPB}=$ cardiopulmonary bypass; $\mathrm{LV}=$ left ventricle.

Table II. Postoperative Univariate Risk Factors for Mortality

\begin{tabular}{lccc}
\hline $\begin{array}{l}\text { Postoperative } \\
\text { Variable }\end{array}$ & $\begin{array}{l}\text { Number } \\
\text { of patients }\end{array}$ & \multicolumn{2}{c}{ Mortality } \\
& Deaths & $p$ \\
\hline Cardiac failure & 5 & 4 & 0.0001 \\
Renal failure & 4 & 2 & 0.042 \\
Respiratory failure & 11 & 3 & 0.62 \\
Bleeding requiring exploration & 6 & 1 & 0.45 \\
TND & 3 & 1 & 0.25 \\
Dysrhythmia & 7 & 2 & 0.12 \\
\hline
\end{tabular}

$\mathrm{TND}=$ temporary neurological dysfunction. 
tors of morbidity included acute dissection, use of circulatory arrest, transfusion of blood and fresh frozen plasma more than 2 units each, cross clamp and cardiopulmonary bypass times (exceeding 90 and 140 minutes, respectively), and performing concomitant procedures. There was no stroke in this series.

\section{DISCUSSION}

The Bentall procedure and its major modifications (aortic button and Cabrol) have been the technique of choice for the composite graft replacement of the ascending aorta and aortic valve in a variety of pathological conditions. Increased postoperative bleeding and pseudoaneurysm formation at the suture lines were reported to be the disadvantages of the classical-Bentall technique. ${ }^{4-5)}$ Excellent results with the button modification have been reported. ${ }^{1,4-9)}$ The drawbacks of this technique have been the risk of damage to the left main coronary, the circumflex artery, or the first septal perforator, and occlusion of these arteries by tension or kinking.

An age exceeding 60, preoperative New York Heart Association (NYHA) class III and IV, non-Marfan status, preoperative dissection, urgent surgery, duration of cardiopulmonary bypass, and male gender were reported to be predictors of mortality in multivariate analysis. ${ }^{4,6,7,9,10)}$ In a report by Midulla and colleagues, acute type A dissection, rupture, new preoperative neurological symptoms, and the Cabrol technique were associated with a higher hospital mortality in univariate analysis, but by multivariate analysis no independent risk factors wrer demonstrated, as in our study. ${ }^{11)}$ Baumgartner, et al reported that NYHA classification, male gender, and urgent surgery were independent risk factors for mortality, which was $0.9 \%$ in Marfan patients undergoing the Bentall procedure. ${ }^{1)}$ There was no in-hospital mortality among 13 patients with Marfan's syndrome in our series.

The emergence of aortic valve calcification and postoperative cardiac failure as univariate predictors of mortality in this series led us to consider that the mortality of a modified Bentall procedure is a consequence of technical errors, which are mainly button related. Severe calcification of the aortic valve involves the annulus and the periannular aortic wall, as in most of our patients. Contrary to pliable and soft tissues of Marfan patients, stiff tissues make the dissection and the preparation of the coronary buttons difficult, and occlusion or stenosis of main coronary arteries more likely by tension or kinking. Four out of 6 in-hospital deaths had calcified bicuspid valves. Development of cardiac failure in patients with preoperative good LV functions is probably due to main coronary artery problems since most of these patients had elevated cardiac enzymes in the post- 
operative period. The univariate predictors of morbidity are not surprising and are associated with prolonged operation time. Our mortality and mid-term survival rates compare favorably with those reported by others. ${ }^{2,3,10)}$

Modified Bentall procedures are safe in general. Meticulous dissection as well as careful handling and positioning of the coronary buttons are of paramount importance in patients with a stiff aortic root since technical errors are more likely to occur.

\section{REFERENCES}

1. Baumgartner WA, Cameron DE, Redmond JM, Greene PS, Gott VL. Operative management of Marfan syndrome: The Johns Hopkins experience. Ann Thorac Surg 1999; 67: 1859-60.

2. Aoyagi S, Kosuga K, Akashi H, Oryoji A, Oishi K. Aortic root replacement with a composite graft: results of 69 operations in 66 patients. Ann Thorac Surg 1994; 58: 1469-75.

3. Svensson LG, Crawford ES, Hess KR, Coselli JS, Safi HJ. Composite valve graft replacement of the proximal aorta: comparison of techniques in 348 patients. Ann Thorac Surg 1992; 54: 427-37.

4. Kouchoukos NT, Wareing TH, Murphy SF, Perillo JB. Sixteen-year experience with aortic root replacement. Results of 172 operations. Ann Surg 1991; 214: 308-20.

5. Lewis CT, Cooley DA, Murphy MC, Talledo O, Vega D. Surgical repair of aortic root aneurysms in 280 patients. Ann Thorac Surg 1992; 53: 38-45.

6. Bachet J, Goudot B, Dreyfus G, et al. Current practice in Marfan's syndrome and annulo-aortic ectasia: aortic root replacement with a composite graft over a twenty-year period. J Card Surg 1997; 12 (2 Suppl): 157-66.

7. Ergin MA, Spielvogel D, Apaydin A, et al. Surgical treatment of the dilated ascending aorta: When and how? Ann Thorac Surg 1999;67:1843-9.

8. Cohn LH, Rizzo RJ, Adams DH, et al. Reduced mortality and morbidity for ascending aortic aneurysm resection regardless of cause. Ann Thorac Surg 1996; 62: 463-8.

9. Gott VL, Gillinov AM, Pyeritz RE, et al. Aortic root replacement. Risk factor analysis of a seventeen-year experience with 270 patients. J Thorac Cardiovasc Surg 1995; 109: 536-44.

10. Westaby S, Katsumata T, Vaccari G. Aortic root replacement with coronary button re-implantation: low risk and predictable outcome. Eur J Cardiothorac Surg 2000; 17: 259-65.

11. Midulla PS, Ergin A, Galla J, et al. Three faces of the Bentall procedure. J Card Surg 1994; 9: 466-81. 